Rapid Communications

\title{
Fabrication of a Carbon Sphere-modified Electrode and Sensitive Determination of Cadmium(II)
}

\author{
Xiangliang NIE ${ }^{*, * *}$ and Weibing $\mathrm{HU}^{*, * * \dagger}$ \\ *Key Laboratory of Biologic Resources Protection and Utilization of Hubei Province, Enshi 445000, P. R. China \\ **School of Chemistry \& Environmental Engineering, Hubei Institute for Nationalities, Enshi 445000, P. R. China
}

\begin{abstract}
A carbon sphere-modified glass carbon electrode was prepared by employing cyclohexanol as a solvent to disperse the carbon spheres efficiently. The resulting electrode exhibits excellent sensitivity to cadmium(II), and a detection limit of $10^{-10} \mathrm{~mol} / \mathrm{L}$ has been obtained, which is one order of magnitude lower than those obtained by other electrodes. Along with immunity from interference of other metal ions, the wide determination range and good linear correlation coefficient would be beneficial to applications of the electrode.
\end{abstract}

(Received January 16, 2010; Accepted January 26, 2010; Published February 10, 2010)

Cadmium is a well-known toxic and carcinogenic substance. The impact of cadmium on the environment should not be underestimated, because long-term exposure to low levels of $\mathrm{Cd}(\mathrm{II})$ can cause vomiting, diarrhea and other gastrointestinal diseases, whilst acute $\mathrm{Cd}$ (II) poisoning can cause kidney disease, and even death. ${ }^{1}$ Therefore the detection of cadmium and other heavy metals has always been one of the major concerns underpinning environmental health and safety issues. Electrode anodic stripping voltammetry is an effective and convenient method to detect $\mathrm{Cd}(\mathrm{II}){ }^{2,3}$

As an alternative carbon material, carbon spheres possess many features that are beneficial to electrochemical properties, such as large surface areas, good electric conductivity, excellent chemical stability and, importantly, a low price. Carbon spheres have thus attracted much research as additives, ${ }^{4,5}$ and are expected to exhibit good performance regarding electrodes. To the best knowledge of the authors, carbon sphere-modified electrodes used to detect heavy-metal ions have never been reported. In this communication, a new modified electrode for the detection of $\mathrm{Cd}(\mathrm{II})$ is described, which may open a route to research on carbon sphere-modified electrodes.

Figure 1 shows SEM images of carbon spheres on glass carbon electrode (GCE) disks dispersed by ethanol (a) and cyclohexanol (b). In Fig. 1a, uniform diameters of $1 \mu \mathrm{m}$ of the carbon spheres were observed, with some areas being blank, an indication of agglomeration. In Fig. 1b, the carbon spheres are equally distributed. A comparison of these two images shows that GCE can be successfully modified by carbon spheres on the effect of cyclohexanol.

The cyclic voltammetric responses were measured in both a PBS of pH 6.0 without (a) and with (b) a $1 \times 10^{-8} \mathrm{~mol} / \mathrm{L}$ solution of $\mathrm{Cd}(\mathrm{II})$ as shown in Fig. 2A. Oxidation peaks can be seen at $-0.6( \pm 0.01) \mathrm{V}$ in Figs. $2 \mathrm{Aa}$ and $2 \mathrm{Ab}$, which were the characteristic peak of CS-GCE in PBS. Compared with the cyclic voltammogram in the solution without $\mathrm{Cd}$ (II), a sharp reduction peak was observed in CS-GCE as soon as a solution

$\dagger$ To whom correspondence should be addressed.

E-mail: chemistryhu@qq.com of $\mathrm{Cd}^{2+}$ was added into the PBS, suggesting that the carbon spheres were electro-catalytic and sensitive to $\mathrm{Cd}(\mathrm{II})$.

Figure 2B shows cyclic voltammograms of CS-GCE in $0.1 \mathrm{~mol} \mathrm{~L}^{-1}$ PBS of $\mathrm{pH} 6.0$ with different concentrations of $\mathrm{Cd}(\mathrm{II})$, and the inset is a linear fitting of the oxidation peak currents with the concentrations of $\mathrm{Cd}^{2+}$. The peak current corresponding to the reduction of $\mathrm{Cd}(\mathrm{II})$ was positively linear with a $\mathrm{Cd}(\mathrm{II})$ concentration in the regions of $5 \times 10^{-9}$ $1.34 \times 10^{-7} \mathrm{~mol} / \mathrm{L}$ and $1.34 \times 10^{-7}-1 \times 10^{-6} \mathrm{~mol} / \mathrm{L}$, with correlation coefficients of 0.9989 and 0.9998 , respectively. The detection limit was $5 \times 10^{-10} \mathrm{~mol} / \mathrm{L}$ with an accumulation time of $200 \mathrm{~s}$. Multiple determinations $(n=18)$ revealed a relative standard deviation of $3 \%$ for $1 \times 10^{-8} \mathrm{~mol} / \mathrm{L} \mathrm{Cd}(\mathrm{II})$, confirming the significant reproducibility of the modified electrode. The detection limit of the CS-GCE is one order of magnitude lower than those reported using other electrodes. ${ }^{6,7}$ Such a lower detection limit and wide detection range would be beneficial to applications of the electrode.

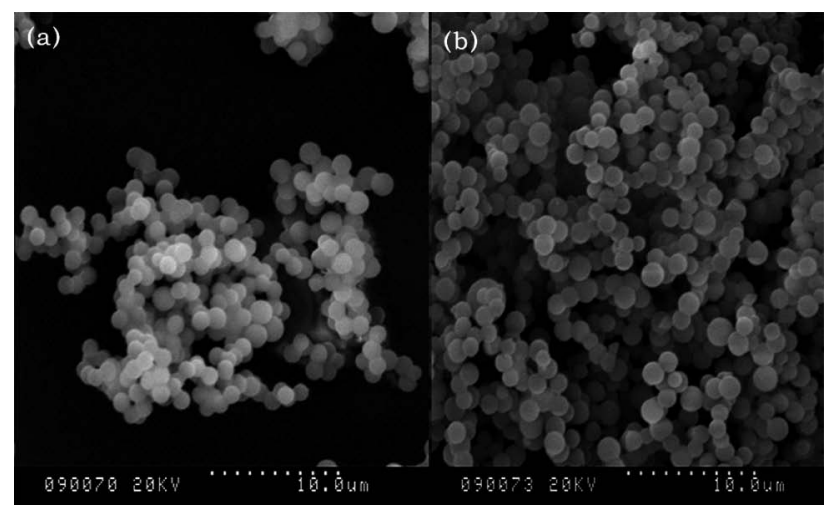

Fig. 1 SEM images of carbon spheres dispersed in (a) ethanol and (b) cyclohexanol on a glass carbon electrode. 

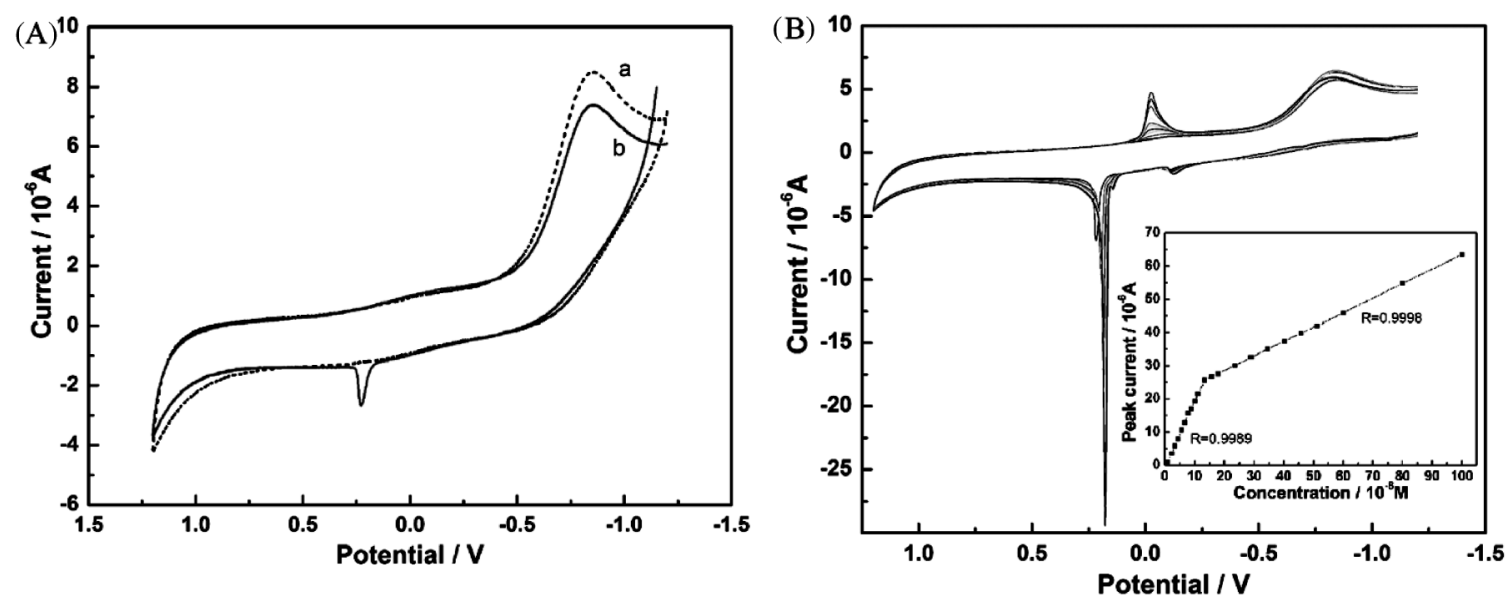

Fig. 2 (A) Cyclic voltammograms of the CS-GCE in $0.1 \mathrm{~mol} \mathrm{~L}^{-1} \mathrm{PBS}$ at $\mathrm{pH} 6.0$ without (a) and with (b) a $1 \times 10^{-8} \mathrm{~mol} / \mathrm{L}$ solution of $\mathrm{Cd}(\mathrm{II}), 0.1 \mathrm{~V} \mathrm{~s}^{-1}$ scan rate between $-1.2 \mathrm{~V}$ and $1.2 \mathrm{~V}$. (B) Cyclic voltammograms of the CS-GCE in $0.1 \mathrm{~mol} \mathrm{~L}^{-1} \mathrm{PBS}$ of $\mathrm{pH} 6.0$ with different concentrations of Cd(II). Insert: linear fitting of the oxidation peak currents with the concentrations of $\mathrm{Cd}(\mathrm{II})$.

\section{Acknowledgements}

This work was financially supported by the National Natural Science Foundation of China (20871044), the Science \& Technology Bureau of Enshi Autonomous Prefecture (2008A28), and the Innovating Program for the graduates in Hubei Institute for Nationalities for funding.

\section{References}

1. K. Prasad, P. Gopikrishna, R. Kala, T. Prasada Rao, and G.
R. K. Naidu, Talanta, 2006, 69, 938.

2. J. Wang, J. M. Lu, S. B. Hocevar, P. A. M. Farias, and B. Ogorevc, Anal. Chem., 2000, 72, 3218.

3. M. Á. G. Rico, M. O. Marín, and E. P. Gil, Talanta, 2009, $80,631$.

4. J. C. Ndamanisha, Y. Hou, J. Bai, and L. Guo, Electrochim. Acta, 2009, 54, 3935.

5. W. Kim, J. B. Joo, N. Kim, S. Oh, P. Kim, and J. Yi, Carbon, 2009, 47, 1407.

6. G. Kefala, A. Economou, and A. Voulgaropoulos, Analyst, 2004, 129, 1082.

7. J. B. Jia, L.Y. Gao, and Z. H. Wang, Electroanalysis, 2007, 19,1845 